\title{
ALOCAÇÕES EM DEBÊNTURES E A PERFORMANCE DOS FUNDOS NO BRASIL
}

\section{ALLOCATION IN CORPORATE BONDS AND FUNDS' PERFORMANCE IN BRAZIL}

\section{ASIGNACIONES EN DEBENTURES Y EL RENDIMIENTO DE LOS FONDOS EN BRASIL}

Recebido em: 17-01-2019

Avaliado em: 23-05-2019

Reformulado em: 07-06-2019

Aceito para publicação em: 14-11-2019

Publicado em: 02-09-2020

Editor Responsável: Tarcísio Pedro da Silva

\author{
Thayse Machado Guimarães ${ }^{1}$ \\ Rodrigo Fernandes Malaquias ${ }^{2}$
}

\section{RESUMO}

O objetivo deste trabalho foi verificar qual a influência da alocação em debêntures no retorno ajustado ao risco dos fundos multimercados brasileiros. Desse modo, a amostra deste estudo foi composta 13.770 observações em um painel balanceado durante o período de dezembro de 2009 a junho de 2018. Foram estimadas quatro regressões para testar a hipótese proposta. As principais evidências demonstram que apesar das debêntures serem títulos expressivos no mercado de capitais brasileiro, somente cerca de $1,77 \%$ das carteiras é alocada nestes títulos de dívida. Ademais, os resultados dos modelos econométricos respondem à hipótese da pesquisa e indicam que as alocações em debêntures tendem a influenciar de maneira positiva na performance dos fundos, expressa pelo Prêmio pelo Risco e pelo Índice de Sharpe. Soma-se a isso a evidência de que os fundos que investem em outros fundos relevam uma performance inferior. Dessa forma, este estudo contribui para a literatura por indicar que gestores de fundos que alocam parte de sua carteira em debêntures apresentam, em média, melhores indicadores de retorno ajustado ao risco.

Palavras-chave: Debêntures; Performance; Retorno Ajustado ao Risco.

\section{ABSTRACT}

This paper aims to verify the influence of allocation in debentures on Brazilian multimarket funds' risk-adjusted return. Thus, this study comprises 13,770 observations in a balanced panel data during the period from December 2009 to June 2018. We estimated four regressions for testing the proposed hypothesis. The main evidence shows that, although debentures are expressive securities in the Brazilian capital market, only about $1.77 \%$ of the portfolios are allocated in these debt securities. Moreover, the main results respond to this study hypothesis and indicate that allocations in debentures tend to positive influence funds' performance. In addition, funds of funds usually have a worse perform. Hence, this study contributes to literature by indicating that fund managers who allocate a portion of their portfolio, on average, showed better indexes for risk-adjusted performance.

\footnotetext{
${ }^{1}$ Doutor em Ciências Contábeis pela Universidade Federal de Uberlândia (UFU); Professor no Instituto Federal do Triângulo Mineiro (IFTM); E-mail: thaysemg.adm@gmail.com

${ }^{2}$ Doutorado em Administração de Empresas pela Fundação Getúlio Vargas (FGV); Professor do Programa de PósGraduação em Ciências Contábeis da Universidade Federal de Uberlândia (UFU); E-mail: rodrigofmalaquias@yahoo.com.br
} 
Keywords: Corporate Bonds; Performance; Risk-Adjusted Return.

\section{RESUMEN}

El objetivo de este trabajo fue verificar cuál es la influencia de la asignación en debentures en el retorno ajustado al riesgo de los fondos multimercados brasileños. De este modo, la muestra de este estudio se compuso de 13.770 observaciones en un panel balanceado durante el período de diciembre de 2009 a junio de 2018. Se calcularon cuatro regresiones para probar la hipótesis propuesta. Las principales evidencias demuestran que a pesar de los debentures ser títulos expresivos en el mercado de capitales brasileño, sólo cerca del $1,77 \%$ de las carteras se asigna en estos títulos. Además, los resultados de los modelos econométricos responden a la hipótesis de la investigación e indican que las asignaciones en debentures tienden a influir de manera positiva en la performance de los fondos, expresada por el Premio por el Riesgo y por el Índice de Sharpe. Se suma a ello la evidencia de que los fondos que invierten en otros fondos reviste una performance inferior. De esta forma, este estudio contribuye a la literatura por indicar que gestores de los fondos multimercados brasileños que asignan parte de su cartera en debentures presentan, en promedio, mejores indicadores de retorno ajustado al riesgo.

Palabras-clave: Debentures; Rendimiento; Retorno Ajustado al Riesgo.

\section{INTRODUÇÃO}

Os fundos de investimento no Brasil são o principal veículo de aplicação dos brasileiros em relação ao volume (Milan \& Eid Júnior, 2017), o que faz a indústria brasileira de fundos ser a décima maior do mundo, com captação de cerca de R \$ 4,1 trilhões em 2017, representando, portanto, 3,04\% do patrimônio líquido mundial (ANBIMA, Consolidado Histórico Fundos de Investimento, 2018). Estes investidores institucionais se configuram como um dos principais subscritores de debêntures no Brasil (Giacomoni \& Sheng, 2013), como visto no ano de 2017, período em que cerca de $61 \%$ do volume emitido destes títulos de dívida foi adquirido por fundos de investimento (ANBIMA, Boletim Mercado de Capitais, 2018).

Conforme Myers (1984), há uma sequência lógica e prioritária de levantamento de recursos por parte das empresas, sustentada pela teoria Pecking Order, também conhecida como Teoria de Hierarquização de Fontes de Financiamento (THFF). De acordo com esta teoria, as organizações priorizam o financiamento interno (fluxo de caixa gerado por adaptações no pagamento de dividendos e pelos lucros obtidos) ao externo. Ademais, dada a necessidade de financiamento externo, optam, primeiramente, pelas emissões de títulos de dívida e, posteriormente, por ações.

As debêntures são um dos principais ativos utilizados pelas empresas para captação de recursos no mercado doméstico (Paiva \& Savoia, 2009), sendo o volume obtido geralmente utilizado como capital de giro e refinanciamento do passivo, isto é, reestruturação das dívidas das empresas emissoras. Elas representam uma alternativa de financiamento das organizações frente às elevadas taxas de juros cobradas pelos bancos comerciais (Godói, Yoshino, \& Oliveira, 2008). Em 2017, a emissão de R $\$ 88$ bilhões de debêntures compreendeu 40\% do total do mercado de capitais brasileiro, o que representa a relevância e o crescimento destes títulos de dívida (ANBIMA, Boletim Mercado de Capitais, 2018).

No entanto, apesar das debêntures serem um dos principais ativos de renda fixa no Brasil, o mercado secundário destes títulos de dívida não é muito desenvolvido, o que gera baixa liquidez quando comparado a outros ativos (Sheng \& Saito, 2008; Araújo, Barbedo, \& Vicente, 2013). A baixa liquidez das debêntures também se justifica pelo fato de o mercado secundário das debêntures ser descentralizado, com operações, em sua maioria, de balcão (Giacomoni \& Sheng, 2013), além de não haver uma estrutura de precificação adequada destes títulos (Araújo et al., 2013). É oportuno mencionar, ainda, livros texto que tratam especificamente do assunto - debêntures (Borba, 2005). 
Estudos anteriores como os de Fisher (1959) e Amihud e Mendelson (1986) já sinalizavam a relevância da liquidez, da comercialização e dos custos de transação na composição dos portfólios de investimento. Segundo estes autores, os investidores almejam um prêmio para investir em ativos menos líquidos, como as debêntures.

A grande maioria dos modelos de precificação de ativos não contempla a liquidez dos títulos, sendo esta correspondente à habilidade de comprar e vender uma grande quantidade de ativos rapidamente a um baixo custo. Os estudos sobre a liquidez do mercado de ações e a do mercado de títulos de dívida têm se desenvolvido separadamente. Entretanto, há interação destes mercados nas operações de comercialização, sendo que conforme as estratégias de alocação dos investidores, há a transferência de riqueza entre ações e título de dívida (Chordia, Sarkar \& Subrahmanyam, 2005).

A relevância das decisões de alocação de ativos na geração de riqueza dos acionistas já é demonstrada na literatura (Clare, Sherman, \& Thomas, 2016) e o processo de seleção de ativos para composição de um portfólio é influenciado pela expectativa da performance futura dos títulos. Então, é importante diversificar os investimentos tendo em vista maior expectativa de retorno (Markowitz, 1952). Desse modo, a estratégia de alocação dos ativos constitui um importante componente na performance dos portfólios (Dichtl, Drobetz, \& Wambach, 2016).

Cerca de $90 \%$ das variações de retorno dos portfólios ao longo do tempo são explicadas pela política de investimento. Visto que diferentes ativos geram diferentes taxas de retorno, o gestor de um portfólio precisa fazer o rebalanceamento da carteira conforme as avaliações inicias de risco e retorno previamente realizadas pelos investidores (Dichtl et al., 2016).

Ressalta-se que fundos de diferentes países geralmente apresentam consideráveis diferenças nas alocações de ativos. Enquanto os fundos de pensão da Europa continental costumam apresentar menos de $20 \%$ investido em ações, os fundos de pensão da União Europeia e dos Estados Unidos são mais agressivos e apresentam cerca de $40 \%$ aplicado em ações (Dichtl et al., 2016).

Nos países emergentes, diferentes fatores influenciam na performance dos fundos; exemplos destes fatores são a alocação de ativos na gestão dos portfólios e as características dos gestores (Maestri \& Malaquias, 2018). Considerando os fundos de investimento brasileiros, no período de 2010 a 2017, geralmente as alocações são feitas em títulos públicos federais (41\%), sendo os investimentos em ações com média de $13 \%$ e as debêntures com pequena representatividade, isto é, somente cerca de 3,52\% do patrimônio líquido dos fundos (ANBIMA, Consolidado Histórico Fundos de Investimento, 2018).

Além das debêntures representarem cerca de $40 \%$ das emissões do mercado de capitais brasileiro, quando considerados os ativos de renda fixa, elas são ainda mais representativas, ou seja, de 2011 a 2017, representaram cerca de 58\% do volume emitido (ANBIMA, Boletim Mercado de Capitais, 2018).

As debêntures são atrativas não só para as empresas emissoras, em função da sua estrutura mais flexível e do baixo do custo de captação dos recursos, quando comparado aos empréstimos, mas também para os investidores, por representarem uma forma de diversificação dos riscos, a qual oferece uma remuneração atrelada a diferentes indexadores e possui uma estrutura flexível de pagamentos dos juros e de amortização do principal (Godói et al., 2008).

Frente ao exposto, este estudo apresenta a seguinte questão de pesquisa: Qual a influência da alocação em debêntures no retorno ajustado ao risco dos fundos multimercados brasileiros? Desse modo, o objetivo geral deste estudo é investigar qual a influência da alocação em títulos de dívida privados no retorno ajustado ao risco dos fundos multimercados brasileiros. De maneira específica, espera-se também identificar os fundos multimercados que alocam algum percentual de suas carteiras em debêntures e compreender o quanto que fatores específicos dos fundos influenciam na alocação das carteiras, bem como no retorno ajustado ao risco.

A relevância deste estudo é justificada por vários fatores. Primeiro ele enfoca nos títulos de dívida, que são ativos expressivos para a economia de países emergentes, como o Brasil (ANBIMA, Boletim Mercado de Capitais, 2018) e de países desenvolvidos, como os Estados Unidos (Chen, 
Ferson, \& Peters, 2010; Clare, O'Sullivan, Sherman, \& Zhu, 2019), mas que estão em estágio inicial nas discussões da literatura (Chen et al., 2010; Cici \& Gibson, 2012; Moneta, 2015). A ênfase em títulos de dívida é especialmente importante, por serem títulos, cuja qualidade do crédito muda ao longo do tempo (Moneta, 2015). Segundo, esta pesquisa aborda os efeitos proporcionados por ativos de renda fixa, sendo estes ativos cada vez mais comuns em fundos de investimento, como os fundos de pensão nos Estados Unidos (Chen et al., 2010). Terceiro, este estudo envolve uma grande amostra de fundos multimercados sobreviventes nos últimos dez anos do mercado brasileiro. Por fim, apesar da literatura sinalizar que geralmente é mais difícil gerar retornos anormais no mercado de renda fixa, em função do pequeno número de traders desinformados (Cici \& Gibson, 2012), este trabalho demonstra potencial de contribuição que pode ser proporcionado pelas debêntures aos fundos multimercados.

A respeito da contribuição empírica, a diversificação dos ativos nas carteiras dos fundos de investimento é um dos fatores que atrai o interesse dos investidores, sejam eles profissionais/qualificados ou não. Soma-se a isso a contribuição para os gestores dos fundos, por destacar como a alocação em diferentes ativos, como os de renda fixa, contribuem para melhor performance dos fundos de investimento. Quanto à originalidade do estudo, buscou-se relacionar nesta pesquisa o retorno ajustado ao risco dos fundos multimercados com um fator que está presente na carteira dos fundos de investimento (títulos de dívida - debêntures) mas que tem sido pouco explorado em estudos acadêmicos. Ao se avaliar a relação entre a alocação em debêntures e o retorno ajustado ao risco dos ativos, tem-se mais uma variável que os investidores podem levar em consideração para realizar investimentos.

Este trabalho se divide em mais cinco seções. O segundo capítulo compreende a revisão da literatura sobre financiamento corporativo e alocação de carteiras e a hipótese do estudo. $\mathrm{O}$ terceiro apresenta as delimitações da pesquisa, a descrição das variáveis e dos modelos econométricos. O quarto capítulo a descrição dos dados e a discussão dos resultados. Por fim, no quinto capítulo, têmse as conclusões do estudo, bem como as sugestões para novas pesquisas.

\section{REVISÃO DA LITERATURA}

Esta seção é composta por dois subtópicos, sendo o primeiro sobre o financiamento corporativo. No segundo tópico, aborda-se de maneira mais detalhada a relação entre decisões de alocação de carteiras e a performance dos fundos, bem como apresenta-se a hipótese de pesquisa.

\subsection{Financiamento Corporativo}

A respeito do financiamento das organizações, Myers (1984) afirma que há uma sequência lógica e prioritária de levantamento de recursos por parte das empresas ao apresentar a teoria Pecking Order, também conhecida como Teoria de Hierarquização de Fontes de Financiamento (THFF). De acordo com a pecking order, as organizações priorizam o financiamento interno, obtido por meio do fluxo de caixa gerado por adaptações no pagamento de dividendos e pelos lucros obtidos. Isso implica dizer que as empresas ajustam o pagamento de dividendos conforme as oportunidades de investimento. Vale destacar que, se o capital gerado internamente for inferior aos investimentos, é preciso recorrer ao financiamento externo por meio de emissão de títulos ao mercado de capitais.

Desse modo, dada a necessidade de financiamento externo, as companhias optam, primeiramente, por títulos de dívida, depois por títulos híbridos, como debêntures conversíveis e, posteriormente, pela emissão de ações (Myers, 1984).

Em relação ao financiamento das empresas brasileiras, os autores Medeiros e Daher (2005) avaliaram a proposta da THFF considerando 132 empresas não-financeiras listadas na bolsa em 2001. Por meio de regressões lineares cross-section, eles confirmam a THFF, pois notaram que as empresas brasileiras recorrem primeiramente aos recursos gerados internamente, seguidos da emissão de títulos de dívida e, em último caso, a emissões de ações. 


\subsection{Alocação de Carteiras e Performance dos Fundos de Investimento}

Os fundos de investimento são intermediários financeiros que possuem o potencial de proporcionar investimentos mais direcionados ao perfil de risco de cada tipo de investidor. Eles são o tipo de investimento prioritário dos investidores de varejo, especialmente pela diversificação dos riscos e pela gestão profissional dos ativos (Babalos, Caporale, \& Philippas, 2015).

Os investidores institucionais constroem e gerenciam seus portfolios baseando-se nos retornos dos ativos alocados, visto que a correlação destes retornos é a "chave" para a comercialização, otimização do portfólio e gerenciamento do risco dos investimentos (Cont \& Wagalath, 2016).

Para Gupta-Mukherjee e Pareek (2016), é importante avaliar a atenção que os gestores dos fundos dedicam às análises dos diferentes ativos disponíveis, não só porque é requerido um esforço para mensurar o valor correto dos ativos, mas também porque este esforço depende da influência dos títulos na performance dos fundos.

Geralmente, os investidores institucionais adotam estratégias de diversificação de seus portfólios com a intenção de aumentar seus retornos, mas existe um limite crítico, acima do qual o rebalanceamento pode gerar perdas para o fundo, por isso a importância de manter parte dos investimentos em um mix fixo (Cont \& Wagalath, 2016).

Os autores Davies, Kat e Lu (2009) analisaram 348 fundos que investem em fundos de hedge. Eles buscaram compreender como as mudanças nas preferências dos investidores resultam em diferenças nas estratégias de alocações e nas classes dos ativos (fundos, ações e outros títulos). Foi utilizado um modelo polinomial, o qual indica quanto deve ser alocado em cada estratégia de fundo de hedge. Os principais resultados indicaram que a combinação dos investimentos em fundos de hedge com ações elevou a assimetria, por isso sugerem que os investidores institucionais utilizem os investimentos em fundos de hedge em substituição de ações e não de títulos de dívida.

Shawky, Dai e Cumming (2012) contemplaram 3548 fundos de hedge e 2058 fundos de investimento em outros fundos durante o período de janeiro de 1994 a dezembro de 2008 e notaram que a diversificação dos ativos nos fundos de hedge realmente importa. Por meio de um modelo de sete fatores, os principais resultados apontaram para uma performance $1,1 \%$ superior dos fundos que diversificaram os setores e as classes de ativos.

Considerando a realidade brasileira, Maestri e Malaquias (2018), ao analisarem 6.002 fundos multimercados de setembro de 2009 a dezembro de 2015, com erros padrão clusterizados por fundo, identificaram que a variável composição das carteiras em renda fixa foi a que mais auxiliou na explicação do retorno ajustado ao risco dos fundos, já que apresentou o maior beta dos modelos estimados. Desse modo, entende-se a importância dos investimentos em renda fixa para a performance dos fundos multimercados, sendo as debêntures um dos ativos de renda fixa mais representativos do mercado de capitais brasileiro (ANBIMA, Boletim Mercado de Capitais, 2018).

Conforme observado na literatura internacional, embora tenha crescido a importância dos fundos de dívida, são poucas as pesquisas sobre a performance destes fundos (Chen et al., 2010; Cici \& Gibson, 2012; Moneta, 2015). As investigações geralmente visam compreender os benefícios da gestão ativa dos fundos de dívida, ao comparar, a performance dos mesmos com as dos fundos de índices (Cici \& Gibson, 2012; Moneta, 2015; Clare et al., 2019).

Clare et al. (2019) realizaram um estudo que envolveu a análise de seletividade dos fundos de dívida, a gestão ativa, expressa pelo "market timing" e a persistência da performance dos fundos. Foram analisados 884 fundos de dívida dos Estados Unidos e 74 fundos benchmarks durante o período de 1998 a 2017. O desempenho dos títulos foi estimado por um modelo multifatores, que contemplou os retornos mensais, bem como fatores de mercado como a curva de juros e o risco do crédito. Ademais, foi inserida uma variável dummy para os períodos de janeiro a setembro de 2008, de modo a identificar a crise financeira.

Para estimar a persistência da performance dos fundos, os alfas foram estimados considerando o retorno de 36 meses. Então, os portfólios foram divididos em decis para análise das performances 
por um mês e depois por três meses. A persistência das performances seria, então, significativa se houvesse redução dos alfas do decil 1 para o 10 (Clare et al., 2019).

As principais evidências sinalizaram retorno anormal positivo dos fundos de dívida em relação aos seus benchmarks, sendo este também calculado livre das taxas de administração. Ademais, o retorno anormal foi observado, especialmente, durante o período de pós-crise financeira. A respeito da gestão ativa, notou-se, predominantemente, relação negativa com os retornos. Por fim, constatouse que não houve persistência da performance nos retornos analisados (Clare et al, 2019).

Os fundos multimercados permitem aos investidores acesso a uma maior diversificação de ativos (renda fixa e variável) e, consequentemente, os investidores têm acesso a diferentes níveis de retorno ajustado ao risco. Desse modo, considerando-se que a alocação dos ativos influência no desempenho dos fundos multimercados, tem-se a seguinte hipótese deste estudo:

H1: Fundos com maiores investimentos em título de dívida (em comparação com seus pares) apresentam melhores indicadores de retorno ajustado ao risco.

\section{METODOLOGIA}

Esta seção descreve os procedimentos metodológicos adotados para a análise empírica. Primeiramente, apresentam-se detalhes relacionados com o período de análise e a amostra do estudo. Em seguida, tem-se a descrição das variáveis do estudo e forma de mensuração. Por fim, são apresentados os modelos econométricos utilizados para o teste da hipótese do estudo.

\subsection{Delimitações do Estudo}

Foram considerados os fundos multimercados, sobreviventes de dezembro de 2009 a junho de 2018, sendo removidos os valores que apresentaram "missing values" para as variáveis da pesquisa. A junção das informações das bases (CVM e software Economática $\left.{ }^{\circledR}\right)$ resultou em painel balanceado com 13.770 observações.

O ano de 2009 representa o início do período de análise, em função do constante crescimento dos fundos de investimento no Brasil, especialmente a partir deste ano (ANBIMA, Consolidado Histórico Fundos de Investimento, 2018). As análises se estendem até junho de 2018 e contempla as informações disponíveis dos fundos multimercados até o primeiro semestre do ano em vigência.

Foram coletadas informações das carteiras dos fundos multimercados para identificação dos investimentos em debêntures. Além disso, estimou-se a performance destes fundos, conforme as variáveis prêmio pelo risco e índice de Sharpe. As variáveis de controle, por sua vez, envolveram características dos fundos multimercados.

\subsection{Seleção das Variáveis}

Há diferentes modelos de multi-fatores utilizados nos estudos para estimar os retornos em excesso dos portfólios (Shawky et al., 2012). Nesse estudo, assim como de Maestri e Malaquias (2018), a performance dos fundos multimercados foi analisada conforme o Índice de Sharpe, obtido pela diferença entre o retorno mensal médio do fundo e média mensal da taxa Selic em cada ano, ponderada pelo desvio padrão dos retornos dos fundos. Ademais, foi estimado o prêmio pelo risco, o qual expressa a diferença do retorno mensal do fundo pela taxa mensal da Selic.

As variáveis independentes deste estudo correspondem às alocações dos fundos em debêntures. Desse modo, assim como Maestri e Malaquias (2018) analisaram as composições das carteiras dos fundos multimercados, separando-as em investimentos variáveis ou fixos, neste estudo, apurou-se a representatividade dos investimentos em debêntures em relação ao total do patrimônio líquido do fundo, ou seja, a variável Deb(\%). De maneira complementar, analisou-se também as alocações dos fundos em debêntures por meio da variável dummy - Deb(DM), cujo valor 1 identifica os fundos que alocaram parte de suas carteiras em pelo menos uma debênture e 0 para os demais. 
Quadro 1 - Variáveis Dependente e Independentes

\begin{tabular}{|c|c|c|c|c|c|}
\hline \multicolumn{2}{|c|}{ Variável } & Descrição & Operacionalização & Sinal & Autores \\
\hline \multirow{2}{*}{ 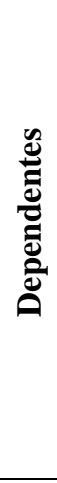 } & Prêmio & $\begin{array}{c}\text { Prêmio pelo } \\
\text { Risco obtido } \\
\text { pelo fundo "i" } \\
\text { no ano "t" }\end{array}$ & $\begin{array}{l}\text { Média da diferença entre o retorno mensal do fundo (i) } \\
\text { e a taxa mensal Selic por ano }\end{array}$ & + & - \\
\hline & Sharpe & $\begin{array}{c}\text { Índice Sharpe } \\
\text { obtido pelo } \\
\text { fundo no ano } \\
\text { " } \mathrm{t} \text { " }\end{array}$ & $\begin{array}{l}\qquad I_{.} S_{i t}=\frac{R_{i}-R_{f}}{\sigma_{i t}} \\
\text { Em que: } I . S_{i t}=\text { Índice de Sharpe para o fundo "i”"; } R_{i}= \\
\text { Retorno mensal médio do fundo "i" por ano; } R_{f}=\text { Média } \\
\text { da taxa Selic mensal em cada ano; } \sigma_{i t}=\text { Desvio-Padrão } \\
\text { dos Retornos do fundo "i" em cada ano. }\end{array}$ & + & $\begin{array}{c}\text { Maestri e } \\
\text { Malaquias } \\
(2018)\end{array}$ \\
\hline \multirow{2}{*}{ 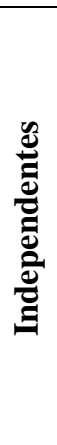 } & $\operatorname{Deb}(\%)$ & $\begin{array}{l}\text { Valor em \% } \\
\text { alocado por } \\
\text { cada fundo "i" } \\
\text { em debêntures }\end{array}$ & \multicolumn{2}{|l|}{$\operatorname{Deb}(\%)_{i t}=\underline{\text { Valor }}$} & $\begin{array}{c}\text { Maestri e } \\
\text { Malaquias } \\
(2018)^{*}\end{array}$ \\
\hline & $\operatorname{Deb}(\mathrm{DM})$ & $\begin{array}{l}\text { Variável } \\
\text { dummy que } \\
\text { identifica se o } \\
\text { fundo "i”" } \\
\text { possui algum } \\
\text { valor alocado } \\
\text { em debêntures }\end{array}$ & \multicolumn{2}{|c|}{$\begin{array}{l}\text { Dummy } 1 \text { para os fundos que alocaram algum valor das carteiras } \\
\text { em debêntures em cada ano e } 0 \text { para as demais }\end{array}$} & - \\
\hline
\end{tabular}

Nota: *Os autores Maestri e Malaquias (2018) consideraram o percentual investido em renda fixa e variável e não especificamente em debêntures.

Fonte: Dados da Pesquisa

Vale destacar que ao final de cada ano (2009 a 2017) foi calculado o percentual das carteiras dos fundos multimercados alocado em debêntures, bem como investigadas as carteiras para identificar os fundos que investiram em debêntures nesse período. Em relação às variáveis dependentes, elas foram estimadas conforme dados dos anos subsequentes (2010 a 2018), ou seja, a alocação em debêntures ao final de 2009 foi vinculada ao prêmio pelo risco e ao índice de Sharpe, calculados conforme média das informações mensais das taxas do ano de 2010.

As restrições de investimento, conhecidas como lock-up, são uma forma dos gestores manterem estratégias de longo prazo (Malaquias \& Pontes, 2018) e possibilitam aos investidores um ganho ("prêmio") pela falta de liquidez, isto é, um prêmio de lock-up (Aragon, 2007). Desse modo, os investidores de hedge funds têm maiores expectativas de retorno, o que dá aos administradores maior flexibilidade para gerenciar ativos ilíquidos.

A análise de uma amostra de 4.662 fundos multimercados brasileiros, de janeiro de 2009 a fevereiro de 2016, resultou em um efeito positivo da existência de períodos de restrições de liquidez com a rentabilidade média dos fundos e com o retorno ajustado ao risco. Isso indica que os fundos com períodos de lock-up tendem a apresentar rentabilidade estatisticamente superior que seus pares (Malaquias \& Pontes, 2018). Então, selecionou-se a variável lock-up para controle do modelo deste estudo.

A cobrança da taxa de performance pode sinalizar maior confiança do gestor quanto aos retornos obtidos. Milan e Eid Jr. (2014) analisaram uma amostra de 95 fundos de investimento em ações de janeiro de 2007 a dezembro de 2011 com o intuito de compreender o impacto da rotatividade das carteiras no desempenho dos fundos de investimento. Os principais resultados indicaram relação negativa entre a elevação dos índices e a performance, enquanto que a taxa de performance e o 
tamanho mostraram influência positiva. Ressalta-se que o modelo estimado indica que a cobrança da taxa de performance não resulta em maior retorno aos cotistas, por influenciar apenas na rentabilidade líquida do fundo. Desse modo, nota-se que a taxa de performance é uma variável de controle relevante para análise do desempenho dos fundos de investimento.

Quadro 2 - Variáveis de Controle

\begin{tabular}{|c|c|c|c|c|c|}
\hline \\
\hline & Variável & Descrição & Operacionalização & Sinal & Autores \\
\hline \multirow{3}{*}{ 己ٌ } & $\operatorname{LockUp}(\mathrm{LN})$ & $\begin{array}{c}\text { Período de } \\
\text { Lockup de cada } \\
\text { fundo "i"" por ano } \\
\text { "t" }\end{array}$ & $\begin{array}{c}\text { Logaritmo Natural do número } \\
\text { de dias entre a solicitação de } \\
\text { resgate e o efetivo pagamento } \\
\text { do valor a ser resgatado pelo } \\
\text { cotista } \\
\end{array}$ & + & $\begin{array}{l}\text { Aragon (2007); } \\
\text { Malaquias e Pontes } \\
\text { (2018). }\end{array}$ \\
\hline & TxPerf & $\begin{array}{c}\text { Taxa de } \\
\text { Performance }\end{array}$ & $\begin{array}{c}\text { Dummy } 1 \text { para os fundos que } \\
\text { possuem taxa de performance } \\
\text { em cada ano e } 0 \text { para os } \\
\text { demais }\end{array}$ & - & $\begin{array}{l}\text { Milan e Eid Jr. } \\
\text { (2014). }\end{array}$ \\
\hline & FIC & $\begin{array}{l}\text { Fundos de } \\
\text { Investimento em } \\
\text { Cotas de outros } \\
\text { Fundos }\end{array}$ & $\begin{array}{c}\text { Dummy } 1 \text { para os fundos de } \\
\text { outros fundos e } 0 \text { para os } \\
\text { demais }\end{array}$ & $+/-$ & $\begin{array}{c}\text { Amin e Kat (2003); } \\
\text { Malaquias e Eid. Jr. } \\
\text { (2014); } \\
\text { Milan e Eid Jr. } \\
\text { (2014); } \\
\text { Malaquias e } \\
\text { Mamede (2015); } \\
\text { Borges Júnior e } \\
\text { Malaquias (2018) }\end{array}$ \\
\hline
\end{tabular}

Fonte: Dados da pesquisa

Por fim, considerou-se também a identificação dos fundos de investimento em cotas (FICs). Para Milan e Eid Jr. (2014), estes fundos tendem a adotar uma estratégia de gestão passiva, mantendo os ativos estáveis na carteira. Assim como apresenta a literatura, a performance dos fundos pode ser impactada pelo perfil de investimento, isto é, pela identificação dos FICs, os quais estão sujeitos a dupla cobrança de taxas. Por um lado, Malaquias e Mamede (2015) afirmam que os fundos de investimento em cotas tendem a apresentar melhor performance que os demais fundos de investimento (Malaquias \& Mamede, 2015). Por outro lado, Amin e Kat (2003) sustentam que os FICs geralmente revelam performance inferior. Ademais, estes investidores institucionais podem ter comportamentos diferenciados em distintos momentos da economia, isto é, maior performance em períodos de crise e menor em períodos de não-crise (Malaquias \& Eid Jr., 2014).

Borges Júnior e Malaquias (2018), ao analisarem a performance de 1.723 fundos de ações brasileiros, de janeiro de 2005 a março de 2016, notaram que os FICs apresentaram melhor retorno ajustado ao risco que os demais fundos da amostra. Isso indica que, embora a literatura apresente desvantagens associadas a estes fundos, como a dupla cobrança de taxa, a melhor performance observada sinaliza maior vantagem na identificação de ativos que superem o benchmark.

\subsection{Desenvolvimento dos Modelos Econométricos}

Esta pesquisa contemplou dados de corte transversal (i) que dizem respeito ao retorno ajustado ao risco de diferentes fundos multimercados, em função das alocações em títulos de dívida, ao longo de uma série temporal (t), ou seja, compreendeu-se o período de dezembro de 2009 a junho de 2018. Por isso, envolve uma dimensão espacial e uma dimensão temporal, sendo, portanto, mais indicados os modelos de regressões de dados em painel (Greene, 2002).

Este estudo compreende a análise do modelo econométrico descrito na Equação (1) que segue: 


$$
\begin{aligned}
& \text { Performance }_{i t+1} \\
& \qquad \beta_{0}+\beta_{1} \text { Debênture }_{i t}+\beta_{2} \operatorname{Lockup}(L N)_{i t+1}+\beta_{3} \operatorname{TxPerf}_{i t+1}+\beta_{4} F I C_{i t+1}+\mu_{i t}
\end{aligned}
$$

Em que:

$i=$ refere-se ao fundo multimercado "i"

$t=$ refere-se ao tempo

$\beta=$ coeficientes associados às variáveis independentes e de controle

Performance $=$ variáveis dependentes correspondentes ao Prêmio pelo Risco e ao Índice Sharpe Debênture = variáveis independentes correspondentes ao \% alocado em debêntures e a dummy que identifica se o fundo alocou algum valor em alguma debênture

$\operatorname{Lockup}(L N)=$ variável de controle correspondente ao período de lockup

TxPerf = variável de controle (dummy), que identifica se o fundo cobra ou não taxa de performance $F I C=$ variável de controle (dummy), que identifica se o fundo investe ou não em cotas de outros fundos

$u=$ termo de erro das equações

Ressalta-se que foram estimados quatro modelos, sendo que os modelos (1) e (2) compreendem, como variável dependente, o prêmio pelo risco, diferenciando-se, portanto, em relação à variável independente sobre as alocações em debêntures (percentual alocado ou variável dummy). Já os modelos (3) e (4) envolvem a variável dependente índice de Sharpe e se diferenciam em relação às variáveis independentes. Os quatro modelos foram estimados com dados empilhados (Pooled Ordinary Least Squares - POLS) e contemplam dummies para identificação dos anos.

\section{RESULTADOS E DISCUSSÕES}

Assim como mostra a Tabela 1, na amostra estudada, cerca de 50\% dos fundos são fundos que investem em outros fundos. Ademais, em média, $21 \%$ dos fundos multimercados apresentam a cobrança da taxa de performance. Sobre o período de dias entre a solicitação de resgate e o efetivo pagamento, em média o logaritmo foi de 0,863 .

Tabela 1 - Estatística Descritiva das Variáveis do Estudo

\begin{tabular}{cccccc}
\hline Variáveis & N. & Média & DP & Min. & Máx. \\
\hline FIC & 13.770 & 0,496 & 0,500 & 0,000 & 1,000 \\
TxPerf & 13.770 & 0,210 & 0,408 & 0,000 & 1,000 \\
LockUp(LN) & 13.770 & 0,863 & 0,813 & 0,000 & 7,497 \\
Deb(\%) & 13.770 & 1,768 & 5,282 & 0,000 & 90,244 \\
Deb(DM) & 13.770 & 0,234 & 0,423 & 0,000 & 1,000 \\
Premio & 13.770 & $-0,022$ & 0,608 & $-3,739$ & 2,811 \\
Sharpe & 13.770 & 0,272 & 0,606 & 0,000 & 5,248 \\
\hline
\end{tabular}

Fonte: Resultados da Pesquisa

Sobre as variáveis independentes, é pequena a participação das debêntures nas carteiras dos fundos, já que somente cerca de 1,79\% do patrimônio líquido é alocado nestes títulos de dívida. Somase a isso a evidência de que apenas $23 \%$ dos fundos analisados alocam algum percentual de suas carteiras em debêntures.

A respeito das variáveis dependentes, que expressam a performance dos fundos multimercados, conforme o valor do prêmio pelo risco de - 0,022 , entende-se que em média os fundos não apresentam retorno mensal superior à taxa Selic. No entanto, ao ponderar pelo desvio padrão dos retornos, isto é, ao analisar o Índice de Sharpe, em média os fundos analisados entregam retornos positivos (extraordinários) aos cotistas, correspondentes a 0,272. 
Os modelos econométricos foram estimados por regressões lineares múltiplas com dados empilhados (POLS) e erros-padrão clusterizados por gestor. Foram retirados os valores que apresentaram "missing values" para as variáveis do estudo e foi aplicado o comando de winsorização a $1 \%$ nas variáveis dependentes "Prêmio" e "Sharpe". Estes procedimentos resultaram em uma base de dados com 13.770 observações.

$\underline{\text { Tabela } 2 \text { - Resultados dos Modelos de Regressão Linear Múltipla - Prêmio pelo Risco }}$

\begin{tabular}{|c|c|c|c|c|c|c|}
\hline \multirow{2}{*}{ Variáveis } & \multicolumn{3}{|c|}{ Modelo (1) } & \multicolumn{3}{|c|}{ Modelo (2) } \\
\hline & Beta & $P$-valor & Sig. & Beta & $P$-valor & Sig. \\
\hline $\operatorname{Deb}(\%)$ & 0,0025 & 0,0220 & $* *$ & & & \\
\hline Deb(DM) & & & & 0,0281 & 0,1860 & \\
\hline LockUp(LN) & 0,0013 & 0,9160 & & 0,0018 & 0,8870 & \\
\hline TxPerf & 0,0135 & 0,6000 & & 0,0139 & 0,5910 & \\
\hline FIC & 0,0288 & 0,1760 & & 0,0323 & 0,1780 & \\
\hline Constante & 0,0215 & 0,3570 & & 0,0176 & 0,5190 & \\
\hline $\mathrm{n}:$ & & 13.770 & & & 13.770 & \\
\hline $\begin{array}{l}\text { Dummy para } \\
\text { ano: }\end{array}$ & & $\operatorname{sim}$ & & & $\operatorname{sim}$ & \\
\hline $\mathrm{R}^{2}$ - ajustado & & $6,10 \%$ & & & $6,09 \%$ & \\
\hline
\end{tabular}

Erros-Padrão: clusterizados por gestor clusterizados por gestor

Notas: Resultados dos modelos de regressão linear múltipla (Equação 1). Os asteriscos indicam os níveis de significância: * $\mathrm{p}<0,10 ; * * \mathrm{p}<0,05 ; * * * \mathrm{p}<0,01$.

Fonte: Resultados da Pesquisa

A Tabela 2 apresenta os resultados dos modelos estimados com a variável dependente "Prêmio pelo risco". A maioria das variáveis não apresenta relação estatisticamente significante com esta variável dependente. No entanto, ao nível de 5\% de significância, observa-se relação positiva da variável $\operatorname{Deb}(\%)$ com o prêmio. Isso indica que, quanto maior for o percentual que os fundos multimercados alocam em debêntures, maior tende a ser o retorno adicional destes fundos em relação à taxa Selic.

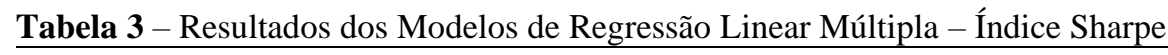

\begin{tabular}{|c|c|c|c|c|c|c|}
\hline \multirow{2}{*}{ Variáveis } & \multicolumn{3}{|c|}{ Modelo (3) } & \multicolumn{3}{|c|}{ Modelo (4) } \\
\hline & Beta & $P$-valor & Sig. & Beta & $P$-valor & Sig. \\
\hline $\operatorname{Deb}(\%)$ & 0,0116 & 0,0010 & $* * *$ & & & \\
\hline $\operatorname{Deb}(\mathrm{DM})$ & & & & 0,0920 & 0,0100 & $* * *$ \\
\hline LockUp(LN) & $-0,0106$ & 0,5080 & & $-0,0100$ & 0,5290 & \\
\hline TxPerf & $-0,0194$ & 0,4470 & & $-0,0175$ & 0,4800 & \\
\hline FIC & $-0,0582$ & 0,0030 & $* * *$ & $-0,0568$ & 0,0040 & $* * *$ \\
\hline Constante & 0,4838 & 0,0000 & $* * *$ & 0,4824 & 0,0000 & $* * *$ \\
\hline $\mathrm{n}:$ & & 13.770 & & & 13.770 & \\
\hline Dummy para ano: & & $\operatorname{sim}$ & & & $\operatorname{sim}$ & \\
\hline $\mathrm{R}^{2}$-ajustado & & $9,63 \%$ & & & $9,01 \%$ & \\
\hline Erros-Padrão: & & zados pc & & & zados po & \\
\hline
\end{tabular}

Notas: Resultados dos modelos de regressão linear múltipla (Equação 1). Os asteriscos indicam os níveis de significância: $* \mathrm{p}<0,10 ; * * \mathrm{p}<0,05 ; * * * \mathrm{p}<0,01$.

Fonte: Resultados da Pesquisa

De maneira complementar, as evidências da Tabela 3 estão alinhadas com o que foi demonstrado na Tabela 2. No modelo 3, a variável Deb(\%) apresenta relação positiva e estatisticamente significante com o Índice de Sharpe, enquanto que, no modelo 4, a variável Deb(DM) 
também se relaciona de maneira positiva com a performance dos fundos multimercados ao nível de $1 \%$ de significância. Estas relações respondem à hipótese $\mathrm{H}_{1}$ da pesquisa e corroboram o trabalho de Maestri e Malaquias (2018), por evidenciar que o investimento em um título de dívida fixa eleva a performance dos fundos multimercados. Portanto, a diversificação dos portfólios é importante para os fundos de investimento, já que está associada a maiores retornos obtidos (Shawky et al., 2012; Cont \& Wagalath, 2016).

No tocante às variáveis de controle, não foram observadas relações estatisticamente significantes com a maioria. Apenas a variável FIC se relaciona negativa e estatisticamente significante com o Índice de Sharpe ao nível de 1\%. Sendo assim, apesar destes fundos geralmente adotarem uma estratégia de gestão passiva, com ativos mais estáveis nas carteiras (Milan \& Eid Jr., 2014), eles revelam uma performance inferior, o que corrobora o trabalho de Aim e Kat (2003).

Os principais resultados desta pesquisa contribuem para reduzir a lacuna encontrada de estudos que envolvem a alocação em títulos de dívida por fundos de investimentos e a performance dos referidos fundos. As evidências obtidas com a análise empírica permitem a formulação de novas hipóteses que podem ser consideradas em pesquisas posteriores, por exemplo, sobre o porcentual alocado em títulos de dívida e o retorno ajustado ao risco na presença de novas variáveis independentes.

\section{CONSIDERAÇÕES FINAIS}

Este estudo amparou-se na relevância da diversificação dos portfólios dos fundos para alcance de maior performance. A partir de evidências da literatura sobre os fundos de investimento e emissões de debêntures, foi analisada a influência da alocação em debêntures no retorno ajustado ao risco dos fundos multimercados brasileiros.

Os fundos de investimento são um dos principais subscritores de debêntures no Brasil e as debêntures são um dos ativos mais representativos do mercado de capitais brasileiro. Desse modo, compreender a relação das alocações em debêntures na performance destes investidores institucionais é relevante não só para a literatura, mas também para os investidores e gestores dos fundos.

Foram analisados quatro modelos econométricos, estimados com dados empilhados, dentre os quais os dois primeiros envolveram a variável Prêmio pelo Risco e os dois últimos o Índice de Sharpe. No total, foram 13.770 observações de dezembro de 2009 a junho de 2018.

Os principais resultados sinalizaram que metade dos fundos investem em outros fundos, ou seja, é composta por FICs. Além disso, apenas $21 \%$ os fundos apresentam cobrança de taxa de performance. Ressalta-se que, embora as debêntures sejam títulos expressivos no mercado de capitais brasileiros, menos de $2 \%$ do patrimônio líquido dos fundos é alocado nestes títulos e somente $23 \%$ dos fundos multimercados da amostra destinaram algum percentual dos investimentos para as debêntures durante o período analisado.

Soma-se a isso o fato de geralmente os fundos apresentarem um prêmio pelo risco negativo com média de -0,022, o que indica retornos de alguns fundos menores que a taxa Selic. Entretanto, ao ponderar pelo desvio padrão, foi observado que o Índice de Sharpe teve média correspondente a 0,272 , o que sinaliza entrega de retornos positivos aos investidores.

Já as evidências dos modelos econométricos respondem à hipótese $\mathrm{H}_{1}$ e indicam que quanto maior for o percentual que os fundos alocam em debêntures ou o fato dos fundos terem algum investimento nestes títulos, maior tende a ser o prêmio pelo risco e o Índice de Sharpe no ano seguinte. Estas relações estatisticamente significantes pelo menos ao nível de 5\% indicam que a diversificação do portfólio, especialmente voltada para títulos de renda fixa, importa para a performance dos fundos multimercados brasileiros.

A principal contribuição da pesquisa está em indicar para a literatura uma variável adicional que pode auxiliar na escolha de fundos para realização de investimentos: o porcentual investido em debêntures. Entretanto, é oportuno ressaltar que os resultados se baseiam em médias, podendo haver 
casos de fundos com alocação em debêntures, mas que registraram retorno ajustado ao risco desfavorável. Os resultados ainda abrem espaço para considerações no que se refere às habilidades de seleção de ativos de gestores de fundos de investimento, uma vez que os resultados também sugerem que os gestores que geralmente selecionam ativos de relativa baixa liquidez para incluir em seus portfolios podem também apresentar habilidade diferenciada para selecionar os demais ativos a serem incluídos na carteira, o que resulta em melhores indicadores de performance.

O estudo, no entanto, apresenta a limitação em relação ao número de fundos multimercados analisados, ou seja, foram analisados somente os fundos sobreviventes no período, o que sinaliza um viés de sobrevivência.

Novos estudos podem ser desenvolvidos a respeito dessas temáticas, dentre os quais destacase a inclusão de características dos gestores dos fundos, bem como a análise da performance de outros tipos de fundos de investimento, como os fundos de renda fixa.

\section{REFERÊNCIAS}

Amihud, Y., \& Mendelson, H. (1986). Asset pricing and the bid-ask spread. Journal of Financial Economics, 17(2), 223-249.

Amin, G. S., \& Kat, H. M. (2003). Hedge fund performance 1990-2000: Do the "money machines" really add value? Journal of Financial and Quantitative Analysis, 38(2), 251-274.

ANBIMA - Associação Brasileira das Entidades dos Mercados Financeiro e de Capitais. Consolidado Histórico Fundos de Investimento. Disponível em:

http://www.anbima.com.br/pt_br/informar/estatisticas/fundos-de-investimento/fi-consolidadohistorico.htm. Acesso em: 07 jun. 2018.

ANBIMA - Associação Brasileira das Entidades dos Mercados Financeiro e de Capitais. Boletim Mercado de Capitais ANBIMA - 2018. Disponível em:

<http://www.anbima.com.br/pt_br/informar/relatorios/mercado-de-capitais/boletim-de-mercado-decapitais/boletim-de-mercado-de-capitais.htm>. Acesso em: 19 mai. 2018.

Aragon, G. O. (2007). Share restrictions and asset pricing: Evidence from the hedge fund industry. Journal of Financial Economics, 83(1), 33-58.

Araújo, V. G., Barbedo, C. H. S., \& Vicente, J. V. M. (2013). Construção de curva de juros de debêntures no mercado brasileiro utilizando a parametrização de Nelson-Siegel. Revista de Administração, 48(1), 98113. http://dx.doi.org/10.5700/rausp1076

Babalos, V., Caporale, G. M., \& Philippas, N. (2015). Gender, style diversity, and their effect on fund performance. Research in International Business and Finance, 35(1), 5774.

Borba, J. E. T. (2005). Das Debêntures. Ed. Renovar.

Borges Júnior, D. M., \& Malaquias, R. F. (2018). Performance dos Fundos de Investimento em Cotas no Brasil. Revista Catarinense de Ciência Contábil, 17(51), 75-88.

Chen, Y., Ferson, W., \& Peters, H. (2010). Measuring the timing ability and performance of bond mutual funds. Journal of Financial Economics, 98(1), 72-89.

Chordia, T., Sarkar, A., \& Subrahmanyam, A. (2005). An Empirical Analysis of Stock and Bond Market Liquidity. The Review of Financial Studies, 18(1), 85-129.

Cici, G., Gibson, S. (2012). The performance of Corporate Bond Mutual Funds: Evidence Based on Security Level Holdings. Journal of Financial and Quantitative Analisys. 17(1), 159-178.

Clare, A., O'Sullivan, N., Sherman, M., \& Zhu, S. (2019). The performance of US bond mutual funds. International Review of Financial Analysis, 61, 1-8.

Clare, A., Sherman, M. B., \& Thomas, S. (2016). Multi-asset class mutual funds: Can they time the market? Evidence from the US, UK and Canada. Research in International Business and Finance, 36, 212-221.

Cont, R., \& Wagalath, L. (2016). Institutional investors and the dependence structure of asset returns. International Journal of Theoretical and Applied Finance, 19(02), 1-37.

Davies, R. J.; Kat, H. M.; Lu, S. (2009). Fund of hedge funds portfolio selection: A multiple-objective approach. Journal of Derivatives \& Hedge Funds, 15(2), 91-115.

Dichtl, H., Drobetz, W., \& Wambach, M. (2016). Testing rebalancing strategies for stock-bond portfolios across different asset allocations. Applied Economics, 48(9), 772-788. 
Fisher, L. (1959). Determinants of risk premiums on corporate bonds. Journal of Political Economy, 67(3), 217-237.

Giacomoni, B. H., \& Sheng, H. H. (2013). The impact of liquidity on expected returns from Brazilian corporate bonds. Revista de Administração, 48(1), 80-97.

Godói, A. C. D., Yoshino, J. A., \& Oliveira, R. D. D. (2008). Risco de crédito e alocação ótima para uma carteira de debêntures. Estudos Econômicos, 38(2), 349-372.

Greene, W.H. (2002). Econometric Analysis. 5th Edition, Prentice Hall, Upper Saddle River, 802.

Gupta-Mukherjee; S., Pareek, A. (2016). Limited Attention and Portfolio Choice: The Impact of Attention Allocation on Mutual Fund Performance. Working Paper.

Maestri, C. O. N. M., \& Malaquias, R. F. (2018). Aspectos do gestor, alocação de carteiras e desempenho de fundos no Brasil. Revista Contabilidade \& Finanças-USP, 29(76), 82-96.

Malaquias, R. F., \& Eid Junior, W. (2014). Fundos multimercados: desempenho, determinantes do desempenho e efeito moderador. RAM. Revista de Administração Mackenzie, 15(4), 135-163.

Malaquias, R. F., Pontes, G. A. (2018). Restrições de Liquidez em Fundos de Investimentos: uma Resposta aos Vieses Comportamentais? Brazilian Business Review, 15(4), 382-390.

Markowitz, H. M. (1952). Portfolio selection. Journal of Finance, 7(1), 77-91.

Medeiros, O. R. D., \& Daher, C. E. (2005). Testando a teoria de hierarquização de fontes de financiamento nas empresas brasileiras. Revista Contabilidade \& Finanças, 16(37), 37-45.

Milan, P. L. A. B., \& Eid Jr, W. (2014). Elevada Rotatividade de Carteiras e o Desempenho dos Fundos de Investimento em Ações. Revista Brasileira de Finanças, 12(4), 469-497.

Milan, P. L. A. B.; Eid Jr, W. (2017). Um retrato dos fundos de investimento no Brasil. GV EXECUTIVO, 16(3), 34-38.

Moneta, F. (2015). Measuring bond mutual fund performance with portfolio characteristics. Journal of Empirical Finance, 33, 223-242.

Myers, S. C. (1984). The capital structure puzzle. The Journal of Finance, 39(3), 574-592.

Paiva, E. V. S., \& Savoia, J. R. F. (2009). Pricing corporate bonds in Brazil: 2000 to 2004. Journal of Business Research, 62(9), 916-919.

Shawky uias, R. F., \& Mamede, S. D. P. N. (2015). Efeito calendário e finanças comportamentais no segmento de fundos multimercados. Revista de Administração Contemporânea, 19(SPE), 98-116.

Shawky, H. A., Dai, N., \& Cumming, D. (2012). Diversification in the hedge fund industry. Journal of Corporate Finance, 18(1), 166-178.

Sheng, H. H., \& Saito, R. (2008). Liquidez das debêntures no mercado brasileiro. Revista de AdministraçãoRAUSP, 43(2), 176-185. 